\title{
Robotic surgery of head and neck cancers, a narrative review
}

\author{
Farbood kalantari (1,2), Shahin Rajaeih (1,2), Ali Daneshvar (1,2), Zahra Karbasi (1,2), \\ Mohammad Mahdi Salem $(1,2)$ \\ (1) ENT and Head and Neck Research Center and Department, The Five Senses Institute, Iran \\ University of Medical Sciences, Tehran, Iran; (2) Skull Base Research Center, The Five Senses \\ Institute, Iran University of Medical Sciences, Tehran, Iran
}

This article is distributed under the terms of the Creative Commons Attribution Noncommercial License (CC BY-NC 4.0) which permits any noncommercial use, distribution, and reproduction in any medium, provided the original author(s) and source are credited.

\begin{abstract}
Head and neck cancers are the most common cancers in the body. Treatments are determined on the basis of the location and stage of the primary tumor. The goal of treatment is to eliminate the tumor, prevent recurrence or metastasis, and maintain the quality of life. There are several treatments available for the management of head and neck cancers, including surgery, radiation therapy, chemotherapy, new molecular agents, and a combination of them. Transoral robotic technique is a short-time operation using a type of robotic machine in which the patient undergoes anesthesia for a shorter time and the side effects of this operation and the time of hospitalization are less than open surgery. Due to the importance of speed and accuracy in head and neck cancer surgery and the importance of application of robotics in surgery, the present study was designed and implemented to review the application of robotics in the management of head and neck cancers. In this review study, the keywords: application, robotic, surgical, head cancer, transoral robotic surgery (TORS), and neck cancer, were searched in ISI, PubMed, Scopus, Google scholar databases. Related articles written domestically or abroad that have covered areas such as the background of transoral robotic surgery, maintaining organ function and approaches, the advantages and disadvantages of TORS, the affordability of TORS, the combination of TORS with other therapeutic approaches published from 2003 to 2019 were reviewed. The use of robotic surgery for precise operations such as head and neck cancers seems to be essential. More advanced robotic devices are expected to expand the surgery treatment for head and neck cancers as well as the results of using TORS for oncologic optimization and acceptability of results while maintaining organ function and patient's quality of life.
\end{abstract}

Key Words: robotics, surgery, transoral, management, head cancer, neck cancer.

Eur J Transl Myol 30 (2): 297-303, 2020

Cancer involves abnormal cell division and the reproduction of cells that can spread throughout the body. Cancer cells break away from the normal mechanisms of cell division and growth, whereas in a healthy organism there is always a balance between cell division, normal cell death and differentiation. ${ }^{1}$ In general, when head and neck cancer is spoken, the purpose is upper respiratory tract containing the paranasal sinuses, nasal cavity, pharynx, oral cavity, hypopharynx, larynx, esophagus, and neck. ${ }^{2}$ Head and neck cancers are the most common cancers in the body. Head and neck cancers are reported to be 2.8 percent of all cancers annually, with an annual incidence of 55,000,000 new cases and 300,000 deaths worldwide. In India, over $40 \%$ of cancers are head and neck cancers ${ }^{3}$. Nasal cavity and paranasal sinus cancers make up two percent of newly diagnosed cancers. Of the throat cancers, the supraglottis type comprises about $95 \%$ of pharyngeal cancers 4 . Oral cavity malignancies account for about $10 \%$ of all head and neck malignancies. ${ }^{2-4}$ The treatments for head and neck cancer are determined on the basis of location and stage of the primary tumor. The goal of treatment is to remove the tumor, prevent recurrence or metastasis, and maintain quality of life. ${ }^{5}$ There are numerous therapeutic approaches for the treatment of head and neck cancer including surgery, radiation therapy, chemotherapy, prescription of new molecular agents and a combination of these. Gene therapy and immunotherapy are among the treatments under study. ${ }^{6}$ Tumor, patient, and therapist are the factors affecting the treatment choice including cell type and degree of cancer differentiation, size and location of primary lesion and lymph node status, presence of bone involvement, ability to obtain sufficient 
margins in surgery, presence or absence of metastasis, ability to maintain oral-pharyngeal function, including speaking, swallowing and beauty, patient age and general and mental health conditions, surgeon and radiotherapist expertise, and patient preference and cooperation. Robotic surgery is a new technology that promises a lot to the medical world. Robotic surgery promises the world a revolution in the medical field and is one of the topics that is widely discussed today in the field of surgery. A key feature of robotic systems is their ability to associate complex information with physical action to enable them to perform a useful action.This ability to replace, assist, or exceed human capabilities has had a wonderful impact on many aspects of human society including industrial production, search, quality control and laboratory activities. Robots' ability to do things beyond human capability has given them the ability to enter environments that are not possible for humans. ${ }^{5-7}$ Transoral robotic surgery implies a short-term operation using a type of robotic machine in which the patient undergoes anesthesia for a shorter time and has fewer side effects as well as less hospital stay than open surgery. In this surgery, no external incision is made on the patient and its use provides better 3D images of the tumor to the surgeon. ${ }^{8}$ One of the advantages of using robotic surgery is that the surgeon is not required to be present in the operating room and can be anywhere in the world, leading to the possibility of remote surgery. On the progress of open surgery, steel tools replace traditional tools and specific actions are performed (such as controlling muscle contraction). The primary purpose of these smart devices is to reduce or eliminate the tissue damage that is traditionally associated with open surgery ${ }^{9}$ Regarding the importance of speed and accuracy in head

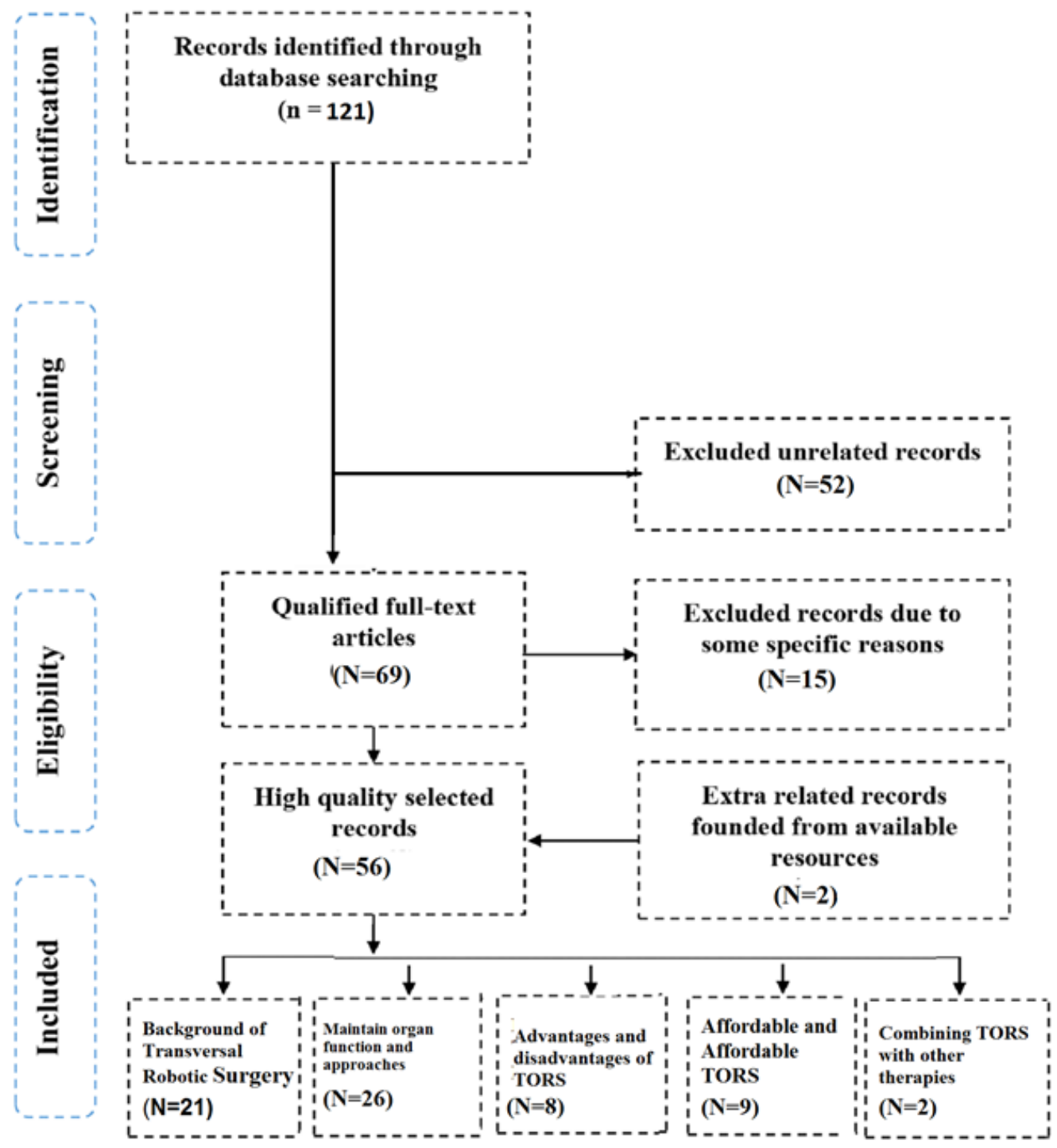

Fig 1. Schematic diagram of the article selection method. 
and neck cancer surgery as well as the aforementioned issues and the importance of application of robotics in surgery, the present study was designed and implemented to evaluate the application of robotics in surgical management of head and neck cancer.

\section{Materials and Methods}

In this review study, we first searched for keywords application, robotic, surgical, head cancer, transoral robotic surgery)TORS(,neck cancer that were selected from the MeSH medical glossary in the Google Scholar ISI, Pub Med, Scopus databases. Related articles written domestically or abroad that have covered areas such as transoral robotic surgery background, organ function maintenance and approaches, the advantages and disadvantages of TORS, the affordability of TORS, the association of TORS with other therapeutic approaches and had been published from 2003 to 2019 were reviewed.A total of 121 articles were extracted, with 15 being deleted due to similarity or duplication, 52 being deleted due to lack of relevance or very poor relevance with the present study, and then 2 articles were added again, , Finally, 56 articles were selected. To achieve the objectives of the study, selected articles were reviewed from the content view. The schematic diagram of the article selection method is shown in Figure (1).

\section{Background of Transoral Robotic Surgery}

In 1998, the Da Vinci robotic surgery system was approved for the first time in laparoscopic surgery by the US Food and Drug Administration and opened a new door to robotic surgery ${ }^{10}$. The first robot-assisted remote operation was performed in September 2001 in which the gallbladder of a 68-year-old woman hospitalized in the East of France was removed by a surgical team in New York. In this surgery, there were about 7,000 kilometers between the surgical team in New York and the patient admitted to a hospital in the East of France.The physician based in New York was overseeing the surgical equipment implanted in the operating room by the robot. The operation lasted for 54 minutes by a high-speed fiber optic line using a laparoscopic robotic surgery system. In this operation the patient resumed normal activity after one week..$^{7-10}$ There are currently about 300 centers worldwide performing robotic surgery covering almost all types of surgery. In 2005, about 75,000 robotic surgeries were performed, although very small compared to conventional surgeries, its number and quality is increasing day by day. ${ }^{11} \mathrm{With}$ the emergence of transoral endoscopic techniques to approach the oropharynx, interest in surgery as a primary treatment increased. ${ }^{12}$ Transoral laser microsurgery (TLM) was initially popular for early stage laryngeal cancers, but became popular in selected areas for oral, pharyngeal and nasal cancers with comparable rates to open surgery and non-surgical treatment. ${ }^{13}$ In an indirect trial study of 204 patients with oral cancer, 3-year overall survival, disease-specific survival and disease-free survival were $86 \%, 88 \%$, and
$82 \%$, respectively, which were comparable to previous concurrent chemoradiation therapy (CCRT) studies. $^{14}$ Benefits of this approach include microscopic visualization of the tumor interface that reduces loss of normal tissue, tactile feedback during surgery, prevents tracheotomy and gastrostomy in most patients. Despite the reported success, TLM admission for oral surgery is mainly restricted to a few centers and this is because TLM often requires sample splitting. Unlike block removal, some surgeons have objected to the operation due to potential for positive margins. ${ }^{10-14}$ The use of the Da Vinci robot for head and neck surgery was first reported in a pork model as a result of submandibular gland removal and neck incision in $2003 .{ }^{15}$ Weinstein et al. (2005) in their study at the University of Pennsylvania stated that there is more practical use of robotic technology for transoral surgery on the dog larynx ${ }^{16}$. Subsequently, a study in 2006 reported the possibility of oral, pharyngeal and nasal surgery ${ }^{17}$. Human tests for robotic surgery (TORS) were then successfully performed in a small group of patients with laryngeal involvement. ${ }^{18}$ At the next stage, a larger group of patients who underwent robotic radical tonsillectomy showed successful results. ${ }^{19}$ Many other groups simultaneously conducted robotic head and neck surgery research and performed a multicenter study examining the safety and risk assessment of TORS. In a group of 192 patients with benign and malignant oral cavity tumors, $4.4 \%$ positive margin and $16 \%$ of side effects were reported. Gastrostomy dependence was reported in $5 \%$ of patients and tracheostomy was performed in $12 \%$ of patients at the beginning. The researchers in this study found that TORS is a low-risk and widely applicable method. ${ }^{20}$ Zevallos et al., in their study aimed at investigating the efficacy of TORS in surgery through the National Cancer Database, reported that although the length of stay had increased from 3 days to 5 days, mortality had decreased. This study highlighted the importance of surgeon experience, patient choice, and multidisciplinary care. ${ }^{21}$ To use the TORS method, it should be noted that not all patients are suitable

Table 1. History of the first robotic surgery

1980: The first laparoscopic surgery

1985: The first robot in neurosurgery

1987: The first Laparoscopic Visual Surgery

1989: The first neurosurgery

1991: The first surgery TURP

1992: The first robot-integrated surgery 
candidates. Patients' inclusion criteria for this technique include extensive examination of the teeth, thymus, jaw transverse dimensions, tongue, and tumor status ${ }^{13}$. And the exclusion criteria stated for TORS include morbid obesity, microstomia, micrognathia, facial and skull abnormalities, and those cases that may prevent robotic access. ${ }^{5,12,22,23}$ Numerous studies have evaluated the safety and efficacy of TORS. Although there is little long-term data since the treatment is new and they are not random, trials have been still implemented in order to compare the efficacy of TORS with chemotherapy and open surgery based on retrospective data. ${ }^{1,6,24}$ The history of the first robotic surgery is shown in Table 1.

\section{Maintaining organ function and approaches:}

There is a wide variety of surgical and non-surgical methods to achieve functional organ maintenance in head and neck cancer. ${ }^{4}$ Chemotherapy and radiotherapy are among the non-surgical methods that are mainly used to treat head and neck cancers. ${ }^{22}$ There are many different surgical methods such as open surgery, minimally invasive techniques such as keyhole surgery and of course transoral techniques. ${ }^{5}$ The first reports of robotic surgery for oral cancer treatment have been described by Hockstein et al, ${ }^{26}$ while in a cadaver model it was performed by O'Malley et al. ${ }^{17}$ in 2009 . The first large prospective case series of TORS for the treatment of oral squamous cell carcinoma was reported by Moore et al. ${ }^{27}$ In the study conducted on 45 patients with T1-T4a, the authors stated that TORS had acceptable oncologic results and safety. Subsequently, in 2012, Weinstein et al. reported initial results of a clinical trials conducted in three different cases; they concluded that TORS seems safe and feasible. ${ }^{20}$ Recently, Moore et al. reported the results of a large group of patients (314 cases) with head and neck cancer treated with TORS in 5 years, stating that the survival rate without local recurrence was $92 \%$ and the overall survival rate was $86 \% .^{10}$ In their study, Almeida et al. reported the 3-year survival and recurrence results, compared TORS with radiotherapy, to be 92.5 and $88.8 \%$, respectively. ${ }^{7}$ As most treatments, TORS can have important treatment-related side effects, the most common and serious complication being postoperative bleeding, with an incidence ranging from 3 to $8 \% .^{23,28,29}$ This potentially fatal complication often required a second surgery to control bleeding. However, expanding data indicate that postoperative bleeding is reduced and avoidable by correcting the status of external carotid artery. ${ }^{30}$ Recently, the use of this treatment is expanding and this is due to the increasing emphasis on organ maintenance and quality of life for patients. ${ }^{31,32} \mathrm{~A}$ growing number of studies have confirmed the success of using TORS method for the treatment of laryngeal cancer. ${ }^{6,31,36-37}$ In a 2016 study by Razafindranaly et al., ${ }^{36}$ which aimed to evaluate the efficacy, safety, and functional outcomes of TORS supraglottic laryngectomy (TORS-SGL) in 84 patients, they stated that the overall results were acceptable. $9.5 \%$ of the patients needed percutaneous gastrostomy, also $24 \%$ needed temporary tracheostomy and $1 \%$ required definitive tracheostomy. Pneumonia was reported in $23 \%$ of the patients and bleeding was reported in $18 \%$ of the patients. TORS have been shown to reduce the risk of postoperative complications. ${ }^{36}$ The authors conclude that TORS is safe and provides functional outcomes with rapid recovery. In addition, regarding the risk of side events, the authors emphasized the importance of using stringent selection criteria to reduce the risk of postoperative complications. ${ }^{36}$ Some reports have described the use of robotic techniques in neck incisions. ${ }^{37,}{ }^{38}$ Regarding the focus on functional results, it can be stated that the most appropriate method of neck incision is the retroauricular method. ${ }^{39}$ However, the transaxillary approach has also been described. ${ }^{40}$ Currently, the existing data for this method is for neck incision, and the results are promising but limited as further studies are needed to determine the need, safety, oncologic results of this method. ${ }^{41}$

\section{Advantages and disadvantages of TORS}

Given the lack of randomized trials and relatively little data on long-term oncologic results, any discussion on TORS to provide a clear picture should be focused on the

Table 2. Advantages and Disadvantages of Robotic Surgery Based on References 42-46

$\begin{array}{ll}\text { Advantage } & \text { Disadvantage } \\ \text { Surgical system advantages } & \text { High costs } \\ \text { Better insite vision(3D) } & \text { Robotic system } \\ \text { Digital camera zoom } & \text { Maintenance system } \\ \text { Camera stability } & \text { Start up } \\ \text { Greater df (Endowrist) } & \text { Bulky size of the robotic system } \\ \text { Improved dexterity } & \text { Sometimes difficult access to patient } \\ \text { Elimination of fulcrum effect } & \text { Separation surgeon from the operating field } \\ \text { Better ergonomics for surgeon } & \text { No tactile feedback } \\ \text { Motion scaling } & \text { Chance of breakdown } \\ \text { Elimination of physiological hand tremor } & \text { Use of } 8 \text { mm ports }\end{array}$


available data, thus further studies are needed. Some of the practical advantages of this method over open surgical procedures are significant reduction in cosmetic and functional side effects, reduced risk of infection and rapid recovery, other advantages of TORS are the ability to 3D panoramic vision, 360 degree range of motion, hand tremor filter. ${ }^{42}$ Despite the potential advantages of TORS, important complications have also been reported. ${ }^{43}$ The most important complication is postoperative bleeding, which is a potentially lifethreatening complication. ${ }^{8}$ The major reported rate of postoperative bleeding is $8.9 \% .^{23,29} \mathrm{~A}$ wide range of other complications in 2017 were reported by Hay et al., including the need for intensive cares such as respiratory compromise aspiration and bleeding, dysphagia and temporary tracheostomy ${ }^{44}$. Several major intraoperative complications include hemorrhage, aspiration pneumonia, tracheostomy, and pharyngeal and nasal fistula. ${ }^{45}$ Hay et al. also found in their study that the complications of TORS decreased over time from one third of patients in 2010 to $10 \%$ in $2015 .{ }^{44}$

\section{Conclusion}

One of the most important issues in the remote surgical system is tactile feedback. Although surgeon robots increase the surgeon's agility, they shake less than the surgeon's natural hand and produce a better view of the field of operation they diminish the ability to sense features of the tissue under operation. Surgeons in usual operations use their tactile sense to get feedback from the tissue under operation during surgery to decide on the status of the tissue under surgery.Also other disadvantages of robotic surgical procedures are the possibility of a twenty-five-second delay on the monitors according to the doctors' conditions, the delay between when the surgeon sees the knife moving until the cut is actually performed less than one-fifth of a second increases the likelihood of cutting in the wrong location. The risk of surgery and the cost of the equipment required for telesurgery are high. ${ }^{46}$

\section{List of acronyms}

TORS - transoral robotic surgery

CCRT -previous concurrent chemoradiation therapy

TORS-SGL- supraglottic laryngectomy

\section{Authors contributions}

All authors played a substantial role in data acquisition and analysis, and also in conception and revision of the manuscript.

\section{Acknowledgments}

None.

\section{Funding}

There was no funding support for this study.

\section{Conflict of Interest}

The authors have no conflicts to disclose.

\section{Ethical Publication Statement}

We confirm that we have read the Journal's position on issues involved in ethical publication and affirm that this report is consistent with those guidelines.

\section{Corresponding Author}

Mohammad Mahdi Salem, 1.ENT and Head and Neck Research Center and Department, The Five Senses Institute, Iran University of Medical Sciences , Tehran, Iran. 2. Skull base Research center, The Five Senses Institute, Iran University of Medical Sciences, Tehran, Iran. Tel :+98- 66525329

ORCID iD: 000-0001-9123-7393

Email: Mmsalem2@gmail.com

\section{E-mails of co-authosr}

Farbood Kalantari: Kalantari.f@iums.ac.ir

ORCID iD: 0000-0001-6566-2345

Shahin Rajaeih: shahin.rajaieh@gmail.com ORCID iD: 000-0002-0842-6781

Ali Daneshvar: Dralidaneshvar@gmail.com

ORCID iD: 0000-0003-3811-5340

Zahra Karbasi: Dr.k74134@gmail.com

ORCID iD: 0000-0003-3226-2286

\section{References}

1. Hay A, Nixon IJ. Recent advances in the understanding and management of oropharyngeal cancer. F1000Res. 2018;7: pii: F1000 Faculty Rev1362.

2. Baskin RM, Boyce BJ, Amdur R, et al. Transoral robotic surgery for oropharyngeal cancer : patient selection and special considerations. Cancer Manag Res. 2018; 10:839-46.

3. Pytynia KB, Dahlstrom KR, Sturgis EM. Epidemiology of HPVassociated oropharyngeal cancer. Oral Oncol. 2014;50:380-6.

4. Mirghani H, Blanchard P. Treatment de-escalation for HPV-driven oropharyngeal cancer: where do we stand? ClinTranslRadiatOncol. 2018;8:4-11.

5. Arora A, Kotecha J, Acharya A, et al. Determination of biometric measures to evaluate patient suitability for transoral robotic surgery. Head Neck. 2015; 37:1254-60.

6. Gorphe P. A contemporary review of evidence for transoral robotic surgery in laryngeal cancer. Front Oncol. 2018; 8:121.

7. de Almeida JR, Byrd JK, Wu R, et al. A systematic review of transoral robotic surgery and radiotherapy for early oropharynx cancer: a systematic review. Laryngoscope. 2014; 124:2096-102.

8. Kelly K, Johnson-Obaseki S, Lumingu J, et al. Oncologic, functional and surgical outcomes of primary Transoral Robotic Surgery for early squamous cell cancer of the oropharynx: a systematic review. Oral Oncol. 2014;50:696-703. 
9. Ward MC, Koyfman SA. Transoral robotic surgery: the radiation oncologist's perspective. Oral Oncol. 2016; 60:96-102.

10. Moore EJ, Abel KM Van, Price DL, et al. Transoral robotic surgery for oropharyngeal carcinoma : surgical margins and oncologic outcomes. Head Neck. 2018;40, 1-9.

11. Gleysteen J, Troob S, Light T, et al. The impact of prophylactic external carotid artery ligation on postoperative bleeding after transoral robotic surgery (TORS) for oropharyngeal squamous cell carcinoma. Oral Oncol. 2017;70:1-6.

12. Holsinger FC, Ferris RL. Transoral endoscopic head and neck surgery and its role within the multidisciplinary treatment paradigm of oropharynx cancer: robotics, lasers, and clinical trials. J ClinOncol Off J Am SocClinOncol. 2015;33:3285-92.

13. Rich JT, Milov S, Lewis JS Jr, et al. Transoral laser microsurgery (TLM) +/- adjuvant therapy for advanced stage oropharyngeal cancer: outcomes and prognostic factors. Laryngoscope. 2009; 119:1709-19.

14. Haughey BH, Hinni ML, Salassa JR, et al. Transoral laser microsurgery as primary treatment for advanced-stage oropharyngeal cancer: a United States multicenter study. Head Neck. 2011; 33:1683-94.

15. Haus BM, Kambham N, Le D, et al. Surgical robotic applications in otolaryngology. Laryngoscope. 2003; 113:1139-44.

16. Weinstein GS, O’Malley BW Jr, Hockstein NG. Transoral robotic surgery: supraglottic laryngectomy in a canine model. Laryngoscope. 2005; 115:1315-9.

17. O’Malley BW Jr, Weinstein GS, Snyder W, et al. Transoral robotic surgery (TORS) for base of tongue neoplasms. Laryngoscope. 2006; 116:146572.

18. Weinstein GS, O’Malley BW Jr, Snyder W, et al. Transoral robotic surgery: supraglottic partial laryngectomy. Ann Otol Rhinol Laryngol. 2007; 116:19-23.

19. Weinstein GS, O’Malley BW Jr, Snyder W, et al. Transoral robotic surgery: radical tonsillectomy. Arch Otolaryngol Head Neck Surg. 2007; 133:1220-6.

20. Weinstein GS, O’Malley BW Jr, Magnuson JS, et al. Transoral robotic surgery: a multicenter study to assess feasibility, safety, and surgical margins. Laryngoscope. 2012; 122:1701-7.

21. Zevallos JP, Mitra N, Swisher-McClure S. Patterns of care and perioperative outcomes in transoral endoscopic surgery for oropharyngeal squamous cell carcinoma. Head Neck. 2016; 38:402-9.

22. Dowthwaite SA, Franklin JH, Palma DA, et al. The role of transoral robotic surgery in the management oforopharyngeal cancer: a review of the literature. ISRN Oncol. 2012;2012:1-14.

23. Chia SH, Gross ND, Richmon JD. Surgeon Experience and Complicationswith Transoral Robotic Surgery (TORS). Otolaryngol Neck Surg. 2013;149:885-92.

24. Yeh DH, Tam S, Fung K, et al. Transoralrobotic surgery vs. radiotherapy for management of oropharyngeal squamouscell carcinoma-A systematic review of the literature. Eur J SurgOncol. 2015;41:1603-14.

25. Rodrigo JP, Coca-Pelaz A, Suárez C. The current role of partial surgeryas a strategy for functional preservation in laryngeal carcinoma. ActaOtorrinolaringol. 2011;62:231-8.

26. Hockstein NG, O’Malley BW, Weinstein GS. Assessment of intraoperativesafety in transoral robotic surgery. Laryngoscope. 2006; 116:165-8.

27. Moore EJ, Olsen KD, Kasperbauer JL. Transoral robotic surgeryfor oropharyngeal squamous cell carcinoma: a prospective study offeasibility and functional outcomes. Laryngoscope. (2009) 119:2156-64.

28. Zenga J, Suko J, Kallogjeri D, et al.Postoperative hemorrhage and hospital revisit after transoral robotic surgery.Laryngoscope. 2017;127:2287-92

29. Mandal R, Duvvuri U, Ferris RL, et al. Analysis of post-transoral robotic-assisted surgery hemorrhage:frequency, outcomes, and prevention. Head Neck. 2015;38:E776-82.

30. Gleysteen J, Troob S, Light T, et al. The impact of prophylactic external carotid artery ligationon postoperative bleeding after transoral robotic surgery (TORS) fororopharyngeal squamous cell carcinoma. Oral Oncol. 2017;70:1-6.

31. Park YM, Keum KC, Kim HR, et al. A clinicaltrial of combination neoadjuvant chemotherapy and transoral robotic surgeryin patients with T3 and T4 laryngo-hypopharyngeal cancer. Ann SurgOncol.2018;25:864-71.

32. Chan JYK, Wong EWY, Tsang RK, et al. Early results of a safety and feasibility clinical trial of a novel singleportflexible robot for transoral robotic surgery. Eur Arch Oto-RhinoLaryngol.2017;274:3993-6.

33. Weinstein GS, O’Malley BW, Snyder W, et al. Transoral roboticsurgery: supraglottic partial laryngectomy. Ann OtolRhinolLaryngol. 2007;116:19-23.

34. Ozer E, Alvarez B, Kakarala K, et al. Clinicaloutcomes of transoral robotic supraglottic laryngectomy. Head Neck. 2012;1158-61.

35. Mendelsohn AH, RemacleM, Van Der Vorst S, et al. Outcomesfollowing transoral robotic surgery: supraglottic laryngectomy. Laryngoscope.2012; 123:208-14.

36. Razafindranaly V, Lallemant B, Aubry K, et al. Clinical outcomes with transoral robotic surgery 


\section{Robotic surgery in head and neck cancers}

Eur J Transl Myol 30 (2): 297-303, 2020

forsupraglottic squamous cell carcinoma: experience of a French evaluationcooperative subgroup of GETTEC. Head Neck. 2016; 38:E1097-101.

37. de Almeida JR, Li R, Magnuson JS, et al. Oncologic outcomes after transoral robotic surgery. JAMA Otolaryngol NeckSurg. 2015; 141:1043.

38. Yee S. Transoral robotic surgery. AORN J. 2017; 105:73-84.

39. Tae K, Ji YB, Song CM, et al. Robotic selective neckdissection by a postauricular facelift approach. Otolaryngol Neck Surg. 2013; 150:394-400.

40. Kim MJ, Lee J, Lee SG, et al. Transaxillaryrobotic modified radical neck dissection: a 5-year assessment ofoperative and oncologic outcomes. SurgEndosc. 2016; 31:1599-606.

41. Byeon HK, Holsinger FC, Kim DH, et al. Feasibility of robot-assisted neck dissection followed bytransoral robotic surgery. $\mathrm{Br} \mathrm{J}$ Oral Maxillofac Surg. 2015;53:68-73.

42. Hammoudi K, Pinlong E, Kim S, et al. Transoralrobotic surgery versus conventional surgery in treatment for squamous cellcarcinoma of the upper aerodigestive tract. Head Neck. 2015;37:1304-9.

43. Voutyrakou DA, Papanastasis A, Chatsikian M, Katrakazas P, Koutsouris D.The Journal of Engineering JoE ; IET Open Access Research. IET Digital Library(2017). Available online at: https://digital-library.theiet.org/content/journals/ 10.1049/joe.2017.0409 (Accessed February 13, 2019).

44. Hay A, Migliacci J, KarassawaZanoni D, et al. Complications following transoral robotic surgery (TORS): adetailed institutional review of complications. Oral Oncol. 2017;67:160-6.

45. Aubry K, Vergez S, de Mones E, et al. Morbidity and mortality revue of the French group of transoral robotic surgery: a multicentric study. J Robot Surg. 2016;10:63-7.

46. Maxwell JH, Rath TJ, Byrd JK, et al. Accuracy of computed tomography to predict extracapsular spread in p16-positive squamous cell carcinoma. Laryngoscope. 2015; 125:1613-8.

47. Dombrée M, Crott R, Lawson G, et al. Costcomparison of open approach, transoral laser microsurgery and transoralrobotic surgery for partial and total laryngectomies. Eur Arch Otorhinolaryngol. 2014;271:2825-34

48. Rudmik L, An W, Livingstone D, et al.Making a case for high-volume robotic surgery centers: a cost-effectivenessanalysis of transoral robotic surgery. J SurgOncol. 2015; 112:155-63.

49. Verma V, Allen PK, Simone CB, et al. Association of treatment athigh-volume facilities with survival in patients receiving chemoradiotherapy for nasopharyngeal cancer. JAMA Otolaryngol Neck Surg. 2017; 144:86-9.

50. Amato L, Fusco D, Acampora A, et al. Volume and health outcomes: evidence from systematic reviews and from evaluation of Italian hospital data. Epidemiol Prev. 2017; 41:1-128.

51. Eskander A, Merdad M, Irish JC, et al. Volumeoutcome associations in head and neck cancer treatment: a systematic review and meta-analysis. Head Neck. 2014; 36:1820-34.

52. Schoppy DW, Rhoads KF, Ma Y, et al. Measuring institutional quality in head and neck surgery using hospital-level data. JAMA Otolaryngol Neck Surg. 2017; 143:1111-6

53. Morche J, Mathes T, Pieper D. Relationship between surgeon volume and outcomes: a systematic review of systematic reviews. Syst Rev. 2016; 5:204.

54. Mäkitie AA, Keski-Säntti H, Markkanen-Leppänen $\mathrm{M}$, et al. Transoral robotic surgery in the Nordic countries: current status and perspectives. Front Oncol. 2018: 8:289.

55. Garas G, Arora A. Robotic head and neck surgery: history, technical evolution and the future. ORL J Otorhinolaryngol Relat Spec. 2018;80:117-24

56. Owadally W, Hurt C, Timmins H, et al. PATHOS: a phase II/III trial of risk-stratified, reduced intensity adjuvant treatment in patients undergoing transoral surgery for Human papillomavirus (HPV) positive oropharyngeal cancer. BMC Cancer. 2015; 15:602.

Submission: December 02, 2019

Revision: December 28, 2019

Acceptance: December 29, 2019 